\title{
Radiofrequency catheter ablation of ventricular tachycardia in pediatric patients
}

\author{
Woo Young Park, Mi Kyoung Song, Gi Beom Kim, Sang Yun Lee, Hye Won Kwon and Eun Jung Bae* (i)
}

\begin{abstract}
Background: Radiofrequency catheter ablation (RFCA) has been accepted as an efficient therapy for tachycardia, and substantial improvement in the outcomes of RFCA in pediatric patients has been seen. However, there is not enough data on the clinical outcomes of RFCA for ventricular tachycardia (VT) in pediatric patients. The objective of this study was to elucidate the efficacy and safety of RFCA for VT in pediatric patients.

Methods: We performed a retrospective study involving 35 consecutive pediatric VT ablation procedures in 28 patients at a single institution.

Results: The median age at ablation was 14.0 years (range 6.9-19.2 years). There were 24 patients with a structurally normal heart and four patients with congenital heart disease (CHD). The left ventricular posteroseptal area was the most common site of $\mathrm{VT}$ origin $(22 / 28,78.6 \%)$. However, there was an unusual case of $\mathrm{VT}$ which involved a papillary muscle as its origin. Acute success was achieved in 30 (85.7\%) of 35 procedures. The recurrence rate after successful RFCA was $14.2 \%$ (5/35) at a median follow-up of 6.7 years (range 1.0-16.7 years). There were five procedural failures due to the inability to induce VT for complete mapping. Ultimately, long-term success was achieved in 27 patients (96.4\%) after repeated procedures and no major complications occurred. Long-term success was associated with VT inducibility $(p=<0.001)$.
\end{abstract}

Conclusions: Difficulty in inducing VT for precise mapping was a significant obstacle to successful RFCA. RFCA was identified as safe and effective therapy to eliminate VT in the selected pediatric VT patients.

Keyword: Ventricular tachycardia, Catheter ablation, Pediatrics, Inducibility, Mapping

\section{Introduction}

Ventricular tachycardia (VT) is uncommon in children; however, VT is critical as it can cause significant hemodynamic problems and degenerate to ventricular fibrillation, resulting in sudden death [1]. Over the past decade, catheter ablation has become an established treatment modality for VT [2]. The current guidelines recommend that the catheter ablation is indicated for patients with symptomatic VT and/or VT with ventricular dysfunction. Radiofrequency catheter ablation (RFCA) is also

*Correspondence: eunjbaek@snu.ac.kr

Department of Pediatrics, Seoul National University Children's Hospital, Seoul National University College of Medicine, 101 Daehang-Ro,

Jongno-gu, Seoul 110-744, South Korea recommended in adult patients with idiopathic VT with a structurally normal heart as class I indication [3]. However, experience with RFCA for pediatric VT is still limited. Consequently, we performed a retrospective study on the safety and efficacy of the procedure in pediatric patients with VT. Furthermore, we assessed the factors associated with successful ablation procedures.

\section{Materials and methods \\ Patients}

We conducted a retrospective study of the 35 consecutive pediatric $\mathrm{VT}$ ablation procedures among 28 patients younger than 20 years who underwent RFCA in the pediatric department between 2002 and January 2020. Clinical data, demographic data, electrocardiograms, 24-h 
Holter monitor records, echocardiograms, and electrophysiologic study reports were reviewed. The patients without significant structural heart disease were classified into the following two categories for comparison of VT characteristics and outcomes: the idiopathic left ventricular tachycardia (LVT) and idiopathic right ventricular tachycardia (RVT). The patients with CHD that required surgery and had significant hemodynamic problems were excluded from this comparison.

Procedural success was defined as the termination of VT in response to RFCA and an inability to re-induce VT with programmed stimulation with or without isoproterenol. Long-term success was defined as no further VT during the follow-up period. Failure was defined as the persistence of spontaneous VT. Early recurrence was defined as transient recurrence within three months, and late recurrence was defined as recurrence after three months. An unfavorable outcome was defined as a procedural failure or a late recurrence. Poor inducibility was defined as:

1. VT stopped frequently by itself, and VT mapping was difficult while VT continued.

2. VT was not well induced reproducibly.

3. VT was not induced by programmed stimulation.

Periodic follow-up included clinical assessment and ECG at 1 month, 3 month, 6 month, 1 year, and 3 years after the RFCA. In addition, treadmill test was usually performed at 6 month to 1 year after the RFCA. This study was approved by the Institutional Review Board of Seoul National University Hospital (1906-063-1039).

\section{Procedures}

The EPS and RFCA were done under various types of conscious sedation: midazolam with ketamine in 13 procedures, midazolam with propofol in eight procedures, general anesthesia in 10 procedures, and local anesthesia in four procedures. Except for rare patients with unstable or incessant VT, antiarrhythmic drugs were discontinued for at least five half-lives. In most patients, two right femoral vein sheaths, two left femoral vein sheaths, and one femoral arterial sheath were installed. EP catheters were introduced into the high right atrium, the His bundle area, the right ventricle, and the coronary sinus, and atrial and ventricular programmed stimulation test was done. For the induction of VT, we performed the repetitive programmed ventricular stimulation with or without isoproterenol. The single, double, and triple ventricular extrastimulation tests were performed in RV apex and RVOT. For the patient with difficult induction, we added burst V pacing as well as LV stimulation study. A biplane angiogram of the chamber of interest was obtained to clarify the anatomic landmarks for the mapping process when required. Three-dimensional mapping using the CARTO (Biosense Webster, Diamond Bar, CA, USA) system was applied in nine procedures. Upon identification of an appropriate site, radiofrequency energy was delivered by a temperature-controlled generator. A bolus dose of heparin (100 unit $/ \mathrm{kg}$ ) was administered intravenously before the initiation of the ablation procedure.

\section{Statistics}

Data analysis was done using SPSS Statistics 25.0 (IBM, Armonk, NY, USA). The data are presented as mean \pm standard deviation or median and ranges if not normally distributed. The categorical variables were compared between the groups using the Mann-Whitney test or Fisher's exact test. Univariate analysis of continuous variables was performed using the Student's $t$-test in case of normally distributed data. A $p$-value of $<0.05$ was considered significant.

\section{Results}

\section{Patient characteristics}

The baseline characteristic of the total patients is presented in Table 1. Median follow-up period of the patients after RF ablation was 6.7 years, ranging from 1.0 years to 16.7 years, and there was one case of followup loss. There were 24 patients with structurally normal hearts and four patients with CHD. Table 2 shows the VT characteristics of the patients with CHD. Patient 1 had small patent ductus arteriosus treated with coil embolization, and Patient 2 had a bicuspid aortic valve with aortic root dilatation, but no significant aortic stenosis or insufficiency was noted. Patient 3 developed VT five days after

\section{Table 1 Baseline characteristics of the total patients}

\begin{tabular}{ll}
\hline & Total patients $(\mathbf{N = 2 8})$ \\
\hline Procedure numbers & 35 \\
Sex (M/F) & $22 / 6$ \\
Congenital heart disease & 4 \\
First age diagnosed ofVT (years) & $13.0(3.6-14.9)$ \\
Age at ablation (years), & $14.0(6.9-19.2)$ \\
Time interval from "1st diagnosed VT" to & $7.5(0.2-95)$ \\
$\quad$ "RFCA"(month) & $65.6(23.0-99.1)$ \\
Weight at RFCA (kg) & 3 \\
LV dysfunction (EF<50\%) & \\
VT morphology & 24 \\
RBBB pattern & 4 \\
LBBB pattern & $6.7(1.0-16.7)$ \\
Follow-up duration (years) &
\end{tabular}

EF Ejection fraction; $L V$ left ventricle; RFCA radiofrequency catheter ablation; $V T$ ventricular tachycardia; $R B B B$ right bundle-branch block; $L B B B$ left bundlebranch block 
Table 2 Ventricular tachycardia in patients with congenital heart disease

\begin{tabular}{|c|c|c|c|c|c|c|c|c|c|}
\hline No & Diagnosis & $\begin{array}{l}\text { Operation } \\
\text { or procedure }\end{array}$ & VT onset & $\begin{array}{l}\text { Ablation age } \\
\text { (years) }\end{array}$ & Sex & VT origin & $\begin{array}{l}\text { Possible } \\
\text { mechanism }\end{array}$ & $\begin{array}{l}\text { Total } \\
\text { procedure } \\
\text { time } \\
\text { (minutes) }\end{array}$ & $\begin{array}{l}\text { Total } \\
\text { fluoroscopy } \\
\text { time (minutes) }\end{array}$ \\
\hline 1 & $\begin{array}{l}\text { Patent ductus } \\
\text { arteriosus }\end{array}$ & $\begin{array}{l}\text { Device closure } \\
\text { with coil }\end{array}$ & $\begin{array}{l}\text { Pre-procedure } \\
\text { (13 years) }\end{array}$ & 14.1 & Male & $\begin{array}{l}\text { LV posterior } \\
\text { fascicular } \\
\text { area }\end{array}$ & Reentry & 315 & 182 \\
\hline \multirow[t]{2}{*}{2} & $\begin{array}{l}\text { Bicuspid aortic } \\
\text { valve }\end{array}$ & None & 8 years & $\begin{array}{l}\text { First ablation } \\
16.2\end{array}$ & Male & $\begin{array}{l}\text { LV posterior } \\
\text { fascicular } \\
\text { area }\end{array}$ & Reentry & 184 & 16.4 \\
\hline & & None & 8 years & $\begin{array}{l}\text { Second abla- } \\
\text { tion* } 17.2\end{array}$ & Male & $\begin{array}{l}\text { LV posterior } \\
\text { fascicular } \\
\text { area }\end{array}$ & Reentry & 189 & 31.3 \\
\hline 3 & $\begin{array}{l}\text { Ebstein } \\
\text { anomaly }\end{array}$ & $\begin{array}{l}\text { Cone proce- } \\
\text { dure, RV } \\
\text { plication }\end{array}$ & $\begin{array}{l}5 \text { days after } \\
\text { operation } \\
\text { (15 years) }\end{array}$ & 15 & Male & $\begin{array}{l}\text { RV plication } \\
\text { site }\end{array}$ & $\begin{array}{l}\text { Enhanced } \\
\text { automaticity }\end{array}$ & 260 & 96.7 \\
\hline 4 & $\begin{array}{l}\text { VSD, noncom- } \\
\text { paction of LV }\end{array}$ & $\begin{array}{l}\text { VSD surgical } \\
\text { repair }\end{array}$ & $\begin{array}{l}13 \text { years after } \\
\text { operation } \\
\text { (13.5 years) }\end{array}$ & 13.5 & Male & $\begin{array}{l}\text { LV posterosep- } \\
\text { tal area }\end{array}$ & Reentry & 232 & \\
\hline
\end{tabular}

$R A$ Right atrium, $R V$ right ventricle; $L V$ left ventricle; $V S D$ ventricular septal defect; $V T$ ventricular tachycardia)

* Antegrade approach after transseptal puncture due to bicuspid aortic valve and ascending aorta dilation

a Cone procedure and right ventricular plication surgery for Ebstein anomaly. As this patient had persistent monomorphic VT despite medical management and direct current cardioversion, RFCA was performed using a 3D CARTO mapping system on postoperative day 17 . Focal VT originating from the RV plication site was confirmed, and it was successfully treated with RFCA. Patient 4 had VT 13 years after ventricular septal defect (VSD) repair.

Two CHD patients (patient 1 and 2) without significant hemodynamic problems and 24 patients without structural heart disease were classified into the idiopathic groups, and 26 patients were further classified into 2 groups according to the origin of VT: the idiopathic left ventricular tachycardia (LVT) and idiopathic right ventricular tachycardia (RVT).

The most common symptom of VT was palpitation, followed by chest discomfort or chest tightness, and eight patients had low cardiac output symptoms or signs, such as syncope, lethargy, and hypotension. The most common indication for RFCA was symptomatic tachycardia (28/28), followed by drug-resistant tachycardia or frequent recurrence with medication $(22 / 28)$. Other indications were LV dysfunction (3/28), syncope (1/28), and seizure $(1 / 28)$.

Two patients developed LV dysfunction and showed a significantly lower heart rate during VT than other patients ( 141.5 beats/min vs. $195.3 \pm 44.5$ beats/min, $p=0.017)$. Among them, one patient was diagnosed with a VSD and ventricular dysfunction at the neonatal period and underwent VSD closure at the age of three months. After VSD closure, ventricular function recovered to the normal range. However, at the age of 14 years, there was a sudden occurrence of VT. The tachycardia was accompanied by LV dilatation and dysfunction (LV ejection fraction, 28\%) and was poorly controlled by cardioversion and antiarrhythmic drugs. Eventually, the patient became hypotensive, and RFCA was performed. The other patient, who was previously healthy until the age of 13 years, presented with VT. LV dysfunction (LV ejection fraction 25\%) was present, and tachycardia was poorly controlled by cardioversion and antiarrhythmic drugs, including amiodarone, verapamil, and lidocaine. Both the patients experienced torsades de pointes during amiodarone infusion under concomitant inotropic support because of severe LV dysfunction.

The youngest RFCA case presented with complaints of abdominal pain at the age of 3 years. The patient had incessant VT from RV origin and was taking sotalol. Although VT was well-controlled initially, frequent recurrences occurred three years later. Subsequently, at six years of age, the patient underwent RFCA. (Fig. 1).

\section{VT management before ablation}

The short-term and long-term managements before VT ablation are summarized in Table 3 . Among the treatments used for acute termination, intravenous verapamil was the most commonly used, with the best effect, especially for idiopathic LVT, followed by DC cardioversion. For long-term medication, verapamil was the most commonly used medication, followed by a beta-blocker. 


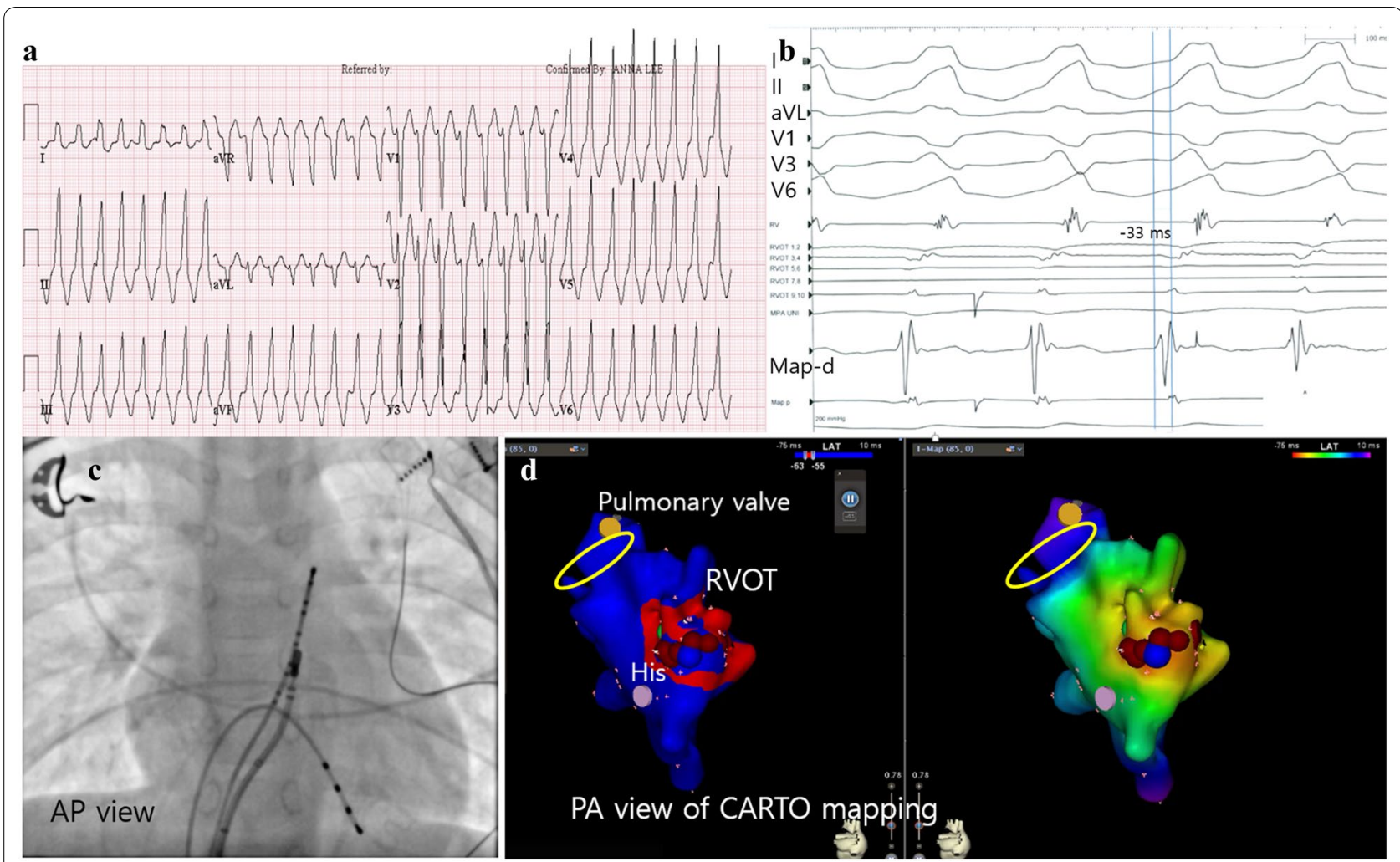

Fig. 1 Radiofrequency ablation in a 6-year-old boy weighing $22 \mathrm{~kg}$ who had recurrent ventricular tachycardia nearly every month despite sotalol $6 \mathrm{mg} / \mathrm{kg} /$ day. a The surface electrocardiography showed left bundle branch block with inferior axis. b-d. During induced ventricular tachycardia, earliest signal (-33 ms) was recorded in RVOT septal area. The VT focus was 6-8 mm above His (pink dot) in this child. Yellow dot: Pulmonary valve annulus, Red dot: Ablation sites, Blue dot: Point of VT termination

Table 3 Management before VT ablation

\begin{tabular}{llll}
\hline & $\begin{array}{l}\text { Idiopathic LV } \\
(\boldsymbol{n = 2 2})\end{array}$ & $\begin{array}{l}\text { Idiopathic } \\
\mathbf{R V}(\boldsymbol{n}=\mathbf{4})\end{array}$ & Total $(\boldsymbol{n = 2 6 )}$ \\
\hline $\begin{array}{llll}\text { Acute termination } \\
\text { IV Verapamil }\end{array}$ & $12\left(11^{*}\right)$ & $2\left(2^{*}\right)$ & $14 / 26$ \\
Adenosine & $12\left(1^{*}\right)$ & 3 & $15 / 26$ \\
Lidocaine & $4\left(2^{*}\right)$ & 2 & $6 / 26$ \\
IV Amiodarone & $3\left(1^{*}\right)$ & $1\left(1^{*}\right)$ & $4 / 26$ \\
IV Diltiazem & $1\left(1^{*}\right)$ & 0 & $1 / 26$ \\
DC cardioversion & $5\left(2^{*}\right)$ & $3\left(2^{*}\right)$ & $8 / 26$ \\
Long-term medication & & & \\
Verapamil & 9 & 1 & $10 / 26$ \\
Beta-blocker & 7 & 2 & $9 / 26$ \\
Sotalol, Amiodarone & 0 & 1 & $1 / 26$ \\
Flecainide & 0 & 1 & \\
No medication & 8 & 1 &
\end{tabular}

IV Intravenous; DC direct current; $L V$ left ventricle; $V T$ ventricular tachycardia * Number of acutely successful cases

\section{Result of VT ablation and arrhythmia characteristics}

The pediatric idiopathic VT characteristics based on the EPS are summarized in Table 4. The LV posteroseptal area was the most common origin site of VT. There were 21 patients $(21 / 22,95.5 \%)$ in the idiopathic LVT group who developed VT originating from the posteroseptal area of the LV. In all the cases of LVT, except for one patient, the ablation catheter was introduced retrogradely through the aortic valve. In the patient with a bicuspid aortic valve, the ablation catheter was initially introduced retrogradely via the aorta. However, the contact force was very low $(0-2 \mathrm{~g})$ due to a bicuspid aortic valve and aortic root dilatation. Therefore, the ablation catheter was introduced anterogradely through the transseptal puncture and consistent contact force (4-11 g) was maintained during the second RFCA session. In the idiopathic RVT group, three patients developed VT in the right ventricular outflow tract (RVOT) septal area, and one patient developed VT in the free wall of the RV body.

The results of the VT ablations are summarized in Table 5. In the present study, the overall acute success rate of idiopathic VT ablation procedures was $84.8 \%$ $(28 / 33)$, the recurrence rate was $17.9 \%(5 / 28)$, and the 
Table 4 Electrophysiological characteristics of idiopathic VT

\begin{tabular}{|c|c|c|}
\hline & Idiopathic LV $(N=22)$ & Idiopathic RV $(N=4)$ \\
\hline Procedure numbers & 28 & 5 \\
\hline Age at ablation (years), Median (range) & 14 (10-19) years & $14(6.9-15)$ years \\
\hline $\operatorname{Sex}(M / F)$ & $18 / 4$ & $2 / 2$ \\
\hline \multicolumn{3}{|l|}{ VT inducibility } \\
\hline Not induced, $n(\%)$ & $2 / 28(7.1 \%)$ & $0 / 5(0.0 \%)$ \\
\hline Poor inducibility, $n(\%)$ & $12 / 28(42.9 \%)$ & $2 / 5(40.0 \%)$ \\
\hline Easy inducibility, n (\%) & $14 / 28(50.0 \%)$ & $3 / 5(60.0 \%)$ \\
\hline \multicolumn{3}{|l|}{ Mapping, $n(\%)$} \\
\hline Activation mapping & $4 / 28(14.3 \%)$ & $3 / 5(60.0 \%)$ \\
\hline Pace mapping & 10/28 (35.7\%) & $3 / 5(60.0 \%)$ \\
\hline Purkinje potential guided mapping & 16/28 (57.1\%) & $0 / 5(0.0 \%)$ \\
\hline 3D-CARTO mapping & $6 / 28(21.4 \%)$ & $1 / 5(20.0 \%)$ \\
\hline \multicolumn{3}{|l|}{ VT focus } \\
\hline LV posteroseptal & $24 / 28(85.7 \%)$ & - \\
\hline LV anteroseptal & $1 / 28(3.6 \%)$ & - \\
\hline LV papillary muscle & $1 / 28(3.6 \%)$ & - \\
\hline RVOT septal & - & $3 / 5(60.0 \%)$ \\
\hline RV free wall & - & $2 / 5(40.0 \%)$ \\
\hline
\end{tabular}

$R V$ Right ventricle; $L V$ left ventricle; $R V O T$ right ventricular outflow tract; $V T$ ventricular tachycardia

Table 5 Results of idiopathic VT ablation

\begin{tabular}{llll}
\hline & Idiopathic LV & Idiopathic RV & Total \\
\hline Number of patients undergoing: & 17 & 3 & 20 \\
1 procedure & 4 & 1 & 5 \\
2 procedures & 1 & 0 & 1 \\
3 procedures & $23 / 28(82.1 \%)$ & $5 / 5(100 \%)$ & $28 / 33(84.8 \%)$ \\
Acute procedure success, $n$ (\%) & $21 / 22(95.5 \%)$ & $4 / 4(100 \%)$ & $25 / 26(96.2 \%)$ \\
Long-term success, $n$ (\%) & & $1(2 \mathrm{~h})$ & 1 \\
Recurrence of VT (interval range) & 0 & $1(17$ months) & 4 \\
Early and transient & $3(3-137$ months) & 0 & 2 \\
Late & & 0 & 1 \\
Complications & 2 & 0 & 1 \\
Transient complete RBBB & $1^{*}$ & $1+$ & \\
Transient arrhythmia & $1+$ & & \\
\hline
\end{tabular}

$R V$ Right ventricle; $L V$ left ventricle; $R B B B$ right bundle branch block

* Ventricular flutter, Torsades de pointes during RFCA

+ Aortic valve regurgitation (Grade II-III)

long-term success rate was $96.2 \%$ (25/26) after six more repeated RFCA sessions. The acute procedural success was $82.1 \%$ in the idiopathic LV group and $100 \%$ in the idiopathic RV group. The long-term success rate was $95.5 \%$ in the idiopathic LV group and $100 \%$ in the idiopathic RV group.

One patient (14 years old) with idiopathic LVT underwent RFCA three times within a year. Initially, tachycardia was found to be LV posterior fascicular VT (Fig. 2a) during the EPS and was successfully ablated guided by the Purkinje potential of the left posterior fascicle. However, three months later, VT recurred and the patient underwent a second RFCA during which the VT failed to ablate because of non-inducibility. VT recurred again (third time) within one month, and emergent RFCA was performed. The recurred VT ECG 


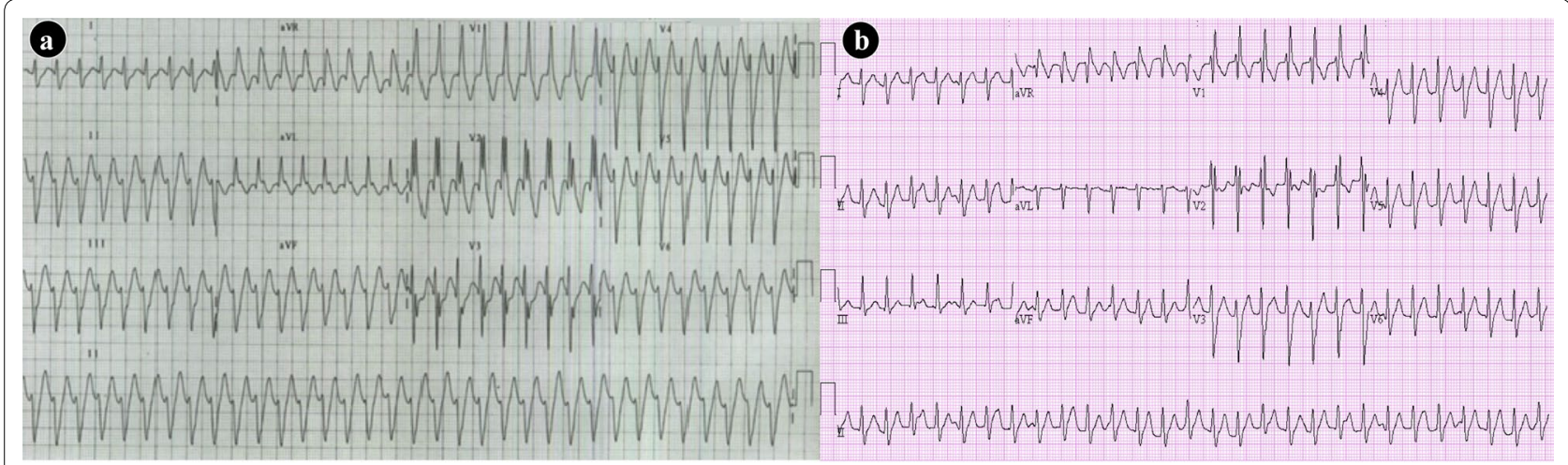

Fig. 2 a The initial VT ECG shows right bundle-branch block and left axis deviation. b The recurred VT ECG shows right bundle-branch block and right axis deviation

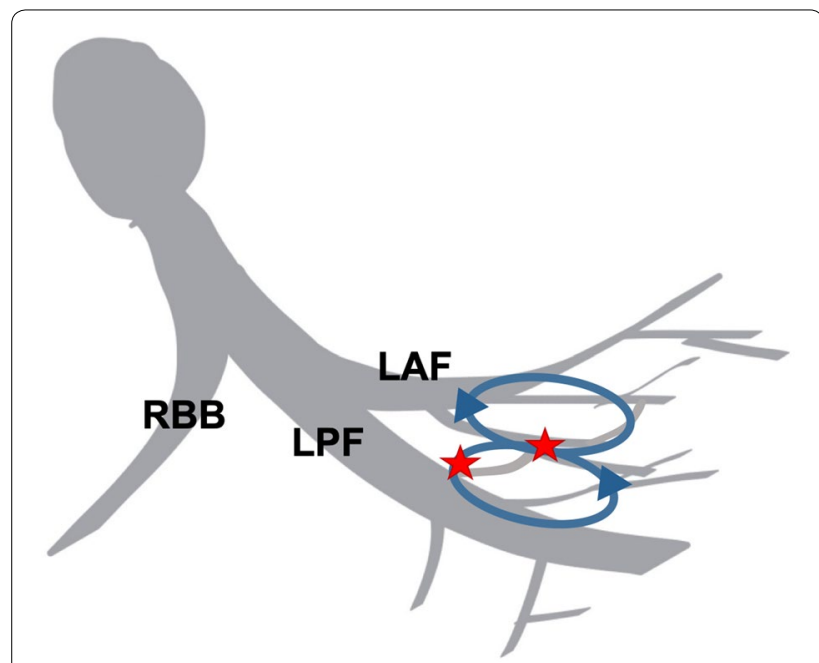

Fig. 3 A schematic representation of the targeted RFCA sites and possible location of the tachycardia circuit. RBB: right bundle branch, LAF: left anterior fascicle, LPF: left posterior fascicle

was different from the previous ECG. The ECG showed right-axis deviation with a right bundle-branch block, suggesting LV anterior fascicular VT (Fig. 2b). VT was eliminated successfully by the third RFCA under CARTO 3D mapping near the anterior fascicle in the LV without recurrence for 39 months. The targeted RFCA sites and possible mechanisms are summarized in Fig. 3.

For the patient with LV papillary muscle VT, the RFCA was applied as guided by intracardiac echocardiography (CARTO-Sound) at the basal part of the posteromedial papillary muscle.

Procedure-related complications were reported in five patients. One patient had a ventricular flutter and torsades de pointes immediately after the first ablation attempt and consequently, defibrillation was required. A transient complete right bundle-branch block was observed in two patients during catheter manipulation, which was self-resolved within minutes or hours. A moderate degree of aortic-valve regurgitation developed in one LVT patient, and a small amount of pericardial effusion developed in one patient after RFCA. However, these findings did not worsen during followup and there were no life-threatening complications.

\section{Prognostic factors of VT ablation}

We performed a univariate analysis of the factors associated with long-term success and unfavorable outcomes. There were 24 procedures in the long-term success group and nine procedures in the unfavorable outcomes group. Heart rate and VT inducibility were statistically different between the two groups. In the long-term success group, the VT rate was lower and VT induction was found to be easier (Table 6). We additionally compared patients with easy VT inducibility and patients with poor VT inducibility based on the ventricular stimulation test. Long-term success was significantly higher in patients with easy inducibility $(17 / 17$ vs. $8 / 14, p=0.004)$, and the recurrence rate was significantly higher in patients with poor inducibility $(0 / 17$ vs. $4 / 14, \mathrm{p}=0.032)$. Long-term success was not associated with the VT mechanism, cardiac anomalies, mapping methods, or ablation age in this series.

\section{Discussion}

This was the first study of the clinical characteristics and prognostic factors of pediatric VT treated with RFCA in a single tertiary center in Korea. The present study showed a relatively high long-term success rate compared to prior studies that reported $74-86 \%$ [46]. Also, a relatively low recurrence rate was observed 
Table 6 Factors in pediatric VT ablation outcomes

\begin{tabular}{|c|c|c|c|}
\hline & $\begin{array}{l}\text { Long-term } \\
\text { success ( } 24 \\
\text { procedures) }\end{array}$ & $\begin{array}{l}\text { Unfavorable } \\
\text { outcome ( } 9 \\
\text { procedures) }\end{array}$ & $p$ Value \\
\hline Ablation age (years) & & & 0.207 \\
\hline Median (range) & $14(7-19)$ & $13(10-16)$ & \\
\hline Sex (male/female) & $19 / 5$ & $6 / 3$ & 0.651 \\
\hline LV/RV origin & $20 / 4$ & $6 / 1$ & 1.000 \\
\hline VT inducibility & & & $<0.001$ \\
\hline Not induced, $n$ & 0 & 2 & \\
\hline Poor inducibility, $n$ & 7 & 7 & \\
\hline Easy inducibility, $n$ & 17 & 0 & \\
\hline VT rate (/min) & & & 0.007 \\
\hline Median & 174 & 229 & \\
\hline Range & $125-247$ & $169-358$ & \\
\hline $\begin{array}{l}\text { QRS duration } \\
\text { (msec) }\end{array}$ & & & 0.519 \\
\hline Median & 135 & 136 & \\
\hline Range & $73-170$ & $117-155$ & \\
\hline
\end{tabular}

$R V$ Right ventricle; $L V$ left ventricle; $V T$ ventricular tachycardia

compared to prior studies that reported rates between 20 and 50\% [5-7]. The safety of RFCA in the management of pediatric VT was also observed to be higher than in previous studies [4-7].

In the adult population, most idiopathic ventricular arrhythmias originate from the outflow tracts [8]. However, in our study, the LV posteroseptal area was the most common originating site of VT, which is consistent with a previous pediatric study [4]. Unlike adults, children with RVOT premature ventricular complex exhibit no symptoms and hardly develop premature ventricular complex-induced cardiomyopathy. Consequently, these patients were not candidates for ablation and were not enrolled in this study. All the patients included in this study had sustained VT run, except one patient with incessant non-sustained RVOT VT runs.

A major factor of unfavorable outcomes in this series was inconsistent VT induction, which led to incomplete map quality. In the case of patients with inconsistent VT induction, ablation was attempted by pace-mapping. Not surprisingly, suboptimal maps resulting from low arrhythmia density correlated with RFCA failure [5]. In the idiopathic LVT, the CARTO mapping was usually used when conventional techniques had failed in previous procedures or turned out to be unsuccessful. In one case, an adequate map was not obtained until the third ablation session. A possible reason behind the relatively high success rate achieved in our institution might rely on the unique technique, in which we ablated an additional insurance lesion slightly proximal to the targeted site to the distal Purkinje signal right after ablating the target site for LVT guided by activation or pacemap.

The management of pediatric patients with VT patients is different according to hemodynamic stability. In cases of hemodynamically unstable sustained VT, the priority is stabilization and electrical cardioversion. Whereas, in cases of hemodynamically stable VT, treatment with antiarrhythmic medications should be initiated [9]. If the VT morphology suggests idiopathic outflow tract VT (left bundle pattern with inferior axis), treatment with intravenous beta-blockers or adenosine may terminate the arrhythmia. Otherwise, intravenous amiodarone is considered as the most effective first choice for pharmacological management [10].

If the VT morphology suggests idiopathic LVT (RBBB with a superior axis or inferior axis), treatment with intravenous verapamil is considered effective for terminating the VT [11]. In the structurally normal heart with normal heart function, idiopathic VTs can be managed with an initial trial of beta-blockers or calcium-channel blockers according to the VT mechanism or origin [10]. Generally, these are used acutely and for long-term suppression of arrhythmias. In our patients, the most commonly administered long-term medication was either verapamil or beta-blockers. Our result cannot be generalized to the entire pediatric VT population, because this study analyzed only selected patients with VT who received RFCA.

The CHD patients might have increased VT burden due to surgical scar and hemodynamic abnormalities before or after surgery [12, 13]. However, the acute long-term procedural success rate in the CHD patients in this series was good and VT did not recur in all patients during follow-up after last procedure.

Ebstein anomaly and tetralogy of Fallot are well known to be associated with ventricular tachyarrhythmia in adults with CHD. However, the 14-year-old boy in our study with Ebstein anomaly interestingly had early postoperative focal VT after a Cone procedure and RV plication surgery. It was published as first successful RFCA case with focal VT from the ventricular plication site [14].

\section{Study limitations}

This study was retrospective, with all the inherent limitations. Since the whole group size was small, the results could have diluted the information. Furthermore, the results from a single-center study cannot automatically be generalized to be representative of other centers. 


\section{Conclusion}

RFCA in pediatric patients with VT was successful without serious complications, regardless of the presence or absence of congenital heart anomalies. Difficulty in inducing VT for precise mapping was a significant obstacle to successful RFCA. This study results confirmed the efficacy and safety of RFCA in the management of pediatric ventricular tachycardia patients.

\begin{abstract}
Abbreviations
RFCA: Radiofrequency catheter ablation; VT: Ventricular tachycardia; RVT: Right ventricular tachycardia; LVT: Left ventricular tachycardia; CHD: Congenital heart disease; RA: Right atrium; RV: Right ventricle; LV: Left ventricle; EPS: Electrophysiology study; VSD: Ventricular septal defect; ECG: Electrocardiography; RBBB: Right bundle-branch block; LBBB: Left bundle-branch block; RVOT: Right ventricular outflow tract; LAF: Left anterior fascicle; LPF: Left posterior fascicle.
\end{abstract}

\section{Acknowledgements}

Not applicable.

\section{Authors' contributions}

WYP acquired and analyzed the data and was a major contributor in writing the manuscript. MKS analyzed the data and substantively revised the manuscript. GBK, SYL, and HWK contributed to the conception and design of the work. EJB designed the work, revised the manuscript and made a final decision on the manuscript. All authors read and approved the final manuscript.

\section{Funding}

Not applicable.

\section{Availability of data and materials}

The datasets used and/or analyzed during the current study are available from the corresponding author upon reasonable request.

\section{Ethics approval and consent to participate}

This study was approved by the Institutional Review Board of Seoul National University Hospital (1906-063-1039).

\section{Consent for publication}

Not applicable

\section{Competing interests}

The authors declare that they have no competing interests.

Received: 31 March 2020 Accepted: 2 October 2020

Published online: 02 November 2020

\section{References}

1. Song MK, Baek JS, Kwon BS, Kim GB, Bae EJ, Noh Cl, et al. Clinical spectrum and prognostic factors of pediatric ventricular tachycardia. Circ J. 2010;74(9):1951-8.

2. Peichl P, Wichterle D, Pavlu L, Cihak R, Aldhoon B, Kautzner J. Complications of catheter ablation of ventricular tachycardia: a single-center experience. Circ Arrhythm Electrophysiol. 2014;7(4):684-90.

3. Al-Khatib SM, Stevenson WG, Ackerman MJ, Bryant WJ, Callans DJ, Curtis $A B$, et al. 2017 AHA/ACC/HRS guideline for management of patients with ventricular arrhythmias and the prevention of sudden cardiac death: a report of the American College of Cardiology/American Heart Association Task Force on Clinical Practice Guidelines and the Heart Rhythm Society. 2018;72(14):e91-e220.

4. Wu J, Chen Y, Ji W, Gu B, Shen J, Fu L, et al. Catheter ablation of ventricular tachycardia in the pediatric patients: a single center experience. Pacing and clinical electrophysiology: PACE; 2019.

5. Morwood JG, Triedman JK, Berul Cl, Khairy P, Alexander ME, Cecchin $F$, et al. Radiofrequency catheter ablation of ventricular tachycardia in children and young adults with congenital heart disease. Heart Rhythm. 2004:1(3):301-8.

6. Collins KK, Schaffer MS, Liberman L, Saarel E, Knecht M, Tanel RE, et al. Fascicular and nonfascicular left ventricular tachycardias in the young: an international multicenter study. J Cardiovasc Electrophysiol. 2013;24(6):640-8.

7. Suzuki T, Nakamura Y, Yoshida S, Yoshida Y, Nakamura K, Sasaki T, et al. Radiofrequency catheter ablation of idiopathic left anterior fascicular ventricular tachycardia in children. Heart Rhythm. 2014;11(11):1948-56.

8. Gard JJ, Asirvatham SJ. Outflow tract ventricular tachycardia. Tex Heart Inst J. 2012:39(4):526.

9. Tang PT, Do DH, Li A, Boyle NG. Team management of the ventricular tachycardia patient. Arrhyth Electrophysiol Rev. 2018;7(4):238-46.

10. deSouza IS, Martindale JL, Sinert R. Antidysrhythmic drug therapy for the termination of stable, monomorphic ventricular tachycardia: a systematic review. Emerg Med J. 2015;32(2):161-7.

11. Reviriego S. Idiopathic fascicular left ventricular tachycardia. E-J ESC Coucil Cardiol Pract. 2010;9:13.

12. Houck CA, Chandler SF, Bogers AJ, Triedman JK, Walsh EP, de Groot NM, et al. Arrhythmia mechanisms and outcomes of ablation in pediatric patients with congenital heart disease. Circ Arrhythm Electrophysiol. 2019;12(11):e007663.

13. Walsh EP, Cecchin FJC. Arrhythmias in adult patients with congenital heart disease. Circulation. 2007:115(4):534-45.

14. Ahn KJ, Song MK, Kim GB, Kim WH, Bae EJ. Successful catheter ablation for ventricular tachycardia after cone procedure in Ebstein anomaly. HeartRhythm Case Reports. 2020;6(2):106.

\section{Publisher's Note}

Springer Nature remains neutral with regard to jurisdictional claims in published maps and institutional affiliations.
Ready to submit your research? Choose BMC and benefit from:

- fast, convenient online submission

- thorough peer review by experienced researchers in your field

- rapid publication on acceptance

- support for research data, including large and complex data types

- gold Open Access which fosters wider collaboration and increased citations

- maximum visibility for your research: over $100 \mathrm{M}$ website views per year

At $\mathrm{BMC}$, research is always in progress.

Learn more biomedcentral.com/submissions 